\title{
Stereotactic body radiation therapy versus video-assisted thoracoscopic surgery in stage I lung cancer: Honesty in the face of uncertainty
}

\author{
Biniam Kidane, MD, MSc, FRCSC
}

\author{
From the Section of Thoracic Surgery, Department of Surgery, Max Rady College of Medicine, University of \\ Manitoba, Winnipeg, Manitoba, Canada. \\ Disclosures: Author has nothing to disclose with regard to commercial support. \\ Received for publication Aug 4, 2017; accepted for publication Aug 19, 2017; available ahead of print Sept 12, \\ 2017. \\ Address for reprints: Biniam Kidane, MD, MSc, FRCSC, Health Sciences Centre, GE-611, 820 Sherbrook St, \\ Winnipeg, Manitoba, Canada R3A-1R9 (E-mail: bkidane@hsc.mb.ca). \\ J Thorac Cardiovasc Surg 2018;155:365-6 \\ $0022-5223 / \$ 36.00$ \\ Copyright (c) 2017 by The American Association for Thoracic Surgery \\ http://dx.doi.org/10.1016/j.jtcvs.2017.08.059
}

Cornwell and colleagues ${ }^{1}$ report that video-assisted thoracoscopic surgery (VATS) conferred better overall survival (OS) and recurrence-free survival (RFS) compared with stereotactic body radiation therapy (SBRT) in patients with clinical stage I lung cancer. Although this population had higher comorbidities, chronic obstructive pulmonary disease, and use of tobacco than populations described in other SBRT versus surgery studies, patients tolerated both treatments well with no mortalities and minimal complications. ${ }^{1}$

Many studies have compared SBRT with surgery in patients with stage 1 lung cancer. The authors aptly note that failure to answer this question lies in our inability to address the fundamental issue of whether the same kinds of patients are being compared. Although this study does not overcome that source of fallibility, it presents interesting data. It compares SBRT with contemporaneous patients treated with VATS. Most studies have compared SBRT with open surgery. VATS is better tolerated than open surgery, results in less pain, and is becoming increasingly common. ${ }^{1,2}$ Thus, it is most appropriate to compare SBRT with VATS.

This study had a small sample size and used propensitymatching strategies to facilitate comparison. Even if perfect propensity matching had been achieved, this study would still fall victim to the ultimate weakness of any nonrandomized study: No matter how well one balances known prognostic factors through statistical means, there are many potential unknown prognostic factors still at play in the background. Perfect propensity matching was not achieved, and this should temper inferences drawn from this study. After propensity matching, only $30 \%$ of matched patients receiving SBRT were actually eligible for surgery. This quickly dispels the illusion of balancing even the known prognostic factors. Another limitation was the residual imbalance in invasive mediastinal staging (IMS), with the SBRT group being more than twice as likely to have received IMS.

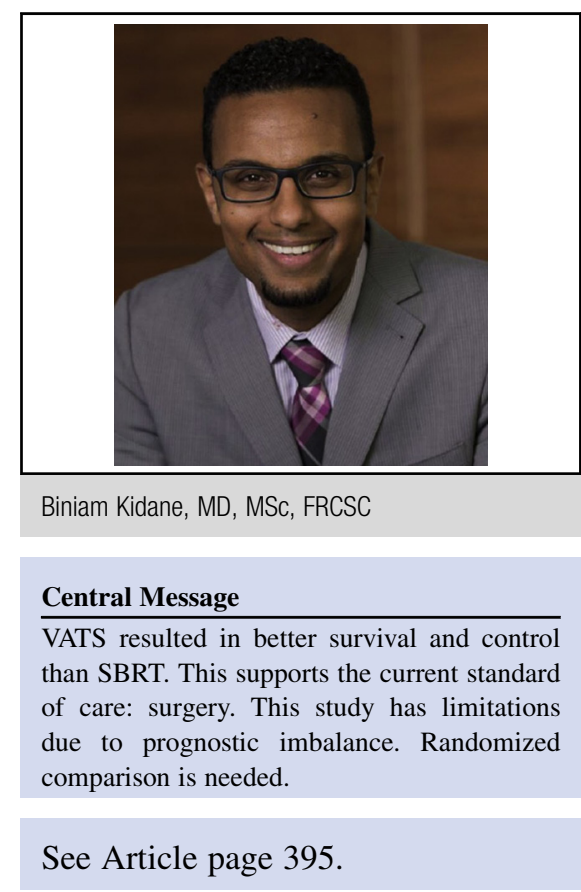

Three-year RFS in the SBRT group was less than half that in the surgery group. Three-year OS was significantly better with surgery. As a thoracic surgeon, these findings align with my biases. As a clinical epidemiologist/methodologist, and as an honest thoracic surgeon, I have to hold my biases in check and evaluate the findings vis-à-vis the limitations. When considering the 2 major matching issues, it is important to evaluate to what extent the matching problem contributes to biasing the results. In the case of the prognostic imbalance conferred by the differential IMS application, we would have expected the dice to be loaded against surgery. Thus, the impact of the IMS bias is less concerning. However, the other residual prognostic imbalance (ie, 30\% of patients receiving SBRT were "operable") is concerning and significantly reduces the credibility of both the OS and RFS results.

In the end, this study supports the current standard of care for operable stage 1 lung cancer: surgery. The authors end appropriately and honestly by calling for a randomized comparison. Some have (inappropriately) used the STARSROSEL meta-analysis as justification for claims of equivalency between surgery and SBRT. ${ }^{3,4}$ We must be cautious not to use evidence such as this article (although it may align with our biases) to make inappropriate claims with overzealous finality about the definitive superiority of surgery. 
We need not all be methodologists, but at the very least we should all strive to be honest surgeons and radiation oncologists.

\section{References}

1. Cornwell LD, Echeverria AE, Samuelian J, Mayor J, Casal RF, Bakaeen FG, et al Video-assisted thoracoscopic lobectomy is associated with greater recurrence-free survival than stereotactic body radiotherapy for clinical stage I lung cancer. $J$ Thorac Cardiovasc Surg. 2018;155:395-402.
2. Donahoe LL, de Valence M, Atenafu EG, Hanna WC, Waddell TK, Pierre AF, et al. High risk for thoracotomy but not thoracoscopic lobectomy. Ann Thorac Surg. 2017;103:1730-5.

3. Chang JY, Senan S, Paul MA, Mehran RJ, Louie AV, Balter P, et al. Stereotactic ablative radiotherapy versus lobectomy for operable stage I non-small-cell lung cancer: a pooled analysis of two randomised trials. Lancet Oncol. 2015;16: 630-7.

4. Meyers BF, Puri V, Broderick SR, Samson P, Keogan K, Crabtree TD. Lobectomy versus stereotactic body radiotherapy for stage I non-small cell lung cancer: post hoc analysis dressed up as level-1 evidence? J Thorac Cardiovasc Surg. 2015;150: 468-71. 